\title{
Human papillomavirus detection using the Abbott RealTime high-risk HPV tests compared with conventional nested PCR coupled to high-throughput sequencing of amplification products in cervical smear specimens from a Gabonese female population
}

Pamela Moussavou-Boundzanga ${ }^{1}$, Ismaël Hervé Koumakpayi², Ingrid Labouba' ${ }^{1}$ Eric M. Leroy ${ }^{1,3}$, Ernest Belembaogo ${ }^{2}$ and Nicolas Berthet ${ }^{1,4,5^{*}}$

\begin{abstract}
Background: Cervical cancer is the fourth most common malignancy in women worldwide. However, screening with human papillomavirus (HPV) molecular tests holds promise for reducing cervical cancer incidence and mortality in low- and middle-income countries. The performance of the Abbott RealTime High-Risk HPV test (AbRT) was evaluated in 83 cervical smear specimens and compared with a conventional nested PCR coupled to high-throughput sequencing (HTS) to identify the amplicons.

Results: The AbRT assay detected at least one HPV genotype in $44.57 \%$ of women regardless of the grade of cervical abnormalities. Except for one case, good concordance was observed for the genotypes detected with the AbRT assay in the high-risk HPV category determined with HTS of the amplicon generated by conventional nested PCR.

Conclusions: The AbRT test is an easy and reliable molecular tool and was as sensitive as conventional nested PCR in cervical smear specimens for detection HPVs associated with high-grade lesions. Moreover, sequencing amplicons using an HTS approach effectively identified the genotype of the hrHPV identified with the AbRT test.
\end{abstract}

Keywords: Abbott RealTime high-risk HPV, Conventional PCR, Human papillomavirus, Screening, Cervical cancer

\section{Background}

Infections with human papillomavirus (HPV) are the most common sexually transmitted infections worldwide [1]. Persistent cervical infection is a high risk factor for cervical cancer, which is the fourth most common

\footnotetext{
* Correspondence: nicolas.berthet@ird.fr

${ }^{1}$ Centre International de Recherches Médicales de Franceville (CIRMF), Department of Zoonosis and Emerging Diseases, 769 Franceville, BP, Gabon ${ }^{4}$ Centre National de Recherche Scientifique (CNRS), UMR3569, 25 rue du docteur Roux, 75724 Paris, France

Full list of author information is available at the end of the article
}

malignancy in women worldwide. Moreover, there is a clear etiological link between the persistence of HPV infections in epithelial cells of the cervical mucosa, precancerous lesions (i.e., cervical intraepithelial neoplasia 3; CIN3) and cervical cancer [2]. Today, more than 200 HPV genotypes have been defined, among which 50 can infect the cervical epithelia. However, only $16 \mathrm{HPV}$ types $(16,18,31,33,34,35,39,45,51,52,56,58,59,66,68,70)$ are classified as high risk (hrHPVs) and 14 (excluding 34 and 59) show strong evidence of a causal link to cervical cancer [3]. 
Based on the clear causal link between hrHPVs and cervical cancer, the guidelines of the American Society for Colposcopy and Cervical Pathology recommend HPV DNA testing instead of cytology to carry out triage in a screened population. Molecular tests for HPV detection may be a good alternative to cytology for early screening because an HPV-negative result is sufficient to declare an extremely low risk of developing CIN3 or worse $(\mathrm{CIN} 3+)$ for 5 years in contrast to a negative cytology result [4]. Other recent studies have confirmed that HPV type identification has significantly higher sensitivity than cytology [5]. Consequently, this higher sensitivity may be the reason behind an increase in the number of false positives, i.e. samples lacking high-grade lesions (CIN2+) [6]. Therefore, a single positive HPV test may be insufficient to identify women who run the risk of developing cervical neoplasia [7]. In response to this caveat, Meijer et al. (2009) published novel guidelines for assessing the performance of a new HPV DNA assay. Molecular assays must detect hrHPV infections that are preferentially associated with $\mathrm{CIN} 2+$, and thus they should have at least $90 \%$ sensitivity with GP5+/6+ primers or the Hybrid Capture 2 (hc2) test [8]. The hc2 test was approved by the United States Food and Drug Administration (FDA) as the gold standard for the detection of 13 hrHPV genotypes in 1999. However, this test has some disadvantages, including the non-discrimination of HPV16 or HPV18 from other hrHPVs and the absence of an internal control [7]. Furthermore, the hc2 test is associated with crossreactivity of the probe mixture with untargeted HPV types [7]. To overcome this limitation, new HPV DNA testing assays (Abbott, Wiesbaden, Germany; LG Life Science, Seoul, Korea, etc.) based on real-time PCR, have been developed and can distinguish HPV16 or HPV18 from other major hrHPVs, and some are currently approved by the FDA for clinical use [7]. These molecular tests are recommended by the Guideline Development Group for the screen-and-treat strategy because their contribution may be greater than visual inspection with acetic acid and/or Lugol's iodine (VIA/ VILI) to reduce cervical cancer and its related mortality. Moreover, their implementation in low- and middleincome countries may be easier than cytology-based screening programs [9]. Furthermore, the quality of the molecular tests is not affected by most bacterial infections concomitant to the HPV infection. Finally, the level of technical training of the healthcare staff has only a minor impact on the performance of the test.

This study was based on the use of the Abbott RealTime High-Risk HPV (AbRT) assay for the detection of HPV in cervical cell samples of women with or without cervical abnormalities. The performance of the test was evaluated in regard to the detection of two main
HPV genotypes, HPV16 and 18, and a panel of 12 hrHPVs, all constituting one single hrHPV category. HPV genotypes identified after sequencing amplicons generated by conventional nested PCR allowed us to determine the non-HPV16/non-HPV18 genotypes detected by the AbRT assay.

\section{Methods}

Study subjects and cervical sample collection

Participating women were selected from a 960 patient cohort previously constituted from March 2013 to January 2014 during a cervical lesion screening program as part of a multi-center cross-sectional study carried out in two hospitals located in Libreville, Gabon [10]. A total of 87 women met both main inclusion criteria, i.e. were aged 25 years or older and presented cervical abnormalities in a VIA/VILI test. Ultimately, 83 women were included in this study and collected specimens were divided into five groups according to cytological analysis: normal (group 1, $n=50$ ), atypical squamous cells of undetermined significance (ASCUS, group 2, $n=12$ ), low-grade squamous intraepithelial lesions (LSIL, group $3, n=7)$, high-grade squamous intraepithelial lesions (HSIL, group 4, $\mathrm{n}=7$ ) and carcinoma (group 5, $\mathrm{n}=7$ ). Women infected by a low-risk HPV genotype - which cannot be detected by the AbRT assay were excluded.

\section{DNA extraction from liquid-based cytology samples}

DNA was extracted from exfoliated cells obtained from liquid-based cytology (LBC) using the DNeasy Blood and Tissue kit (Qiagen, Valencia, CA, USA) according to the manufacturer's instructions. DNA was quantified using the Qubit ${ }^{\oplus}$ dsDNA BR Assay kit with the Qubit 2.0 fluorimeter (Life Technologies, Carlsbad, CA, USA) primarily to confirm the previous DNA purification step.

\section{Assays for HPV detection}

The AbRT assay (Abbott Molecular, Des Plaines, IL, USA) was performed with the m2000rt automated analyzer according to the manufacturer's instructions. Detected HPVs were validated by genotyping a 150 bp fragment of the L1 HPV gene and discriminating between 14 hrHPVs: HPV16, HPV18 and a pool of 12 other hrHPVs (HPV 31, 33, 35, 39, 45, 51, 52, 56, 58, 59, 66 and 68). PCR amplification included $5 \mu \mathrm{L}$ of the extracted DNA sample along with the GP5+/6+ primers designed for use with a high-throughput sequencing approach (HTS): HTS-GP5+: 5' tcg-tcg-gca-gcg-tca-gat-gtgtat-aag-aga-cag-TTG-TTA-CTG-TGG-TAG-ATA-CTA-C 3'; HTS-GP6+: 5' gtc-tcg-tgg-gct-cgg-aga-tgt-gta-taa-gagaca-gGA-AAA-ATA-AAC-TGT-AAA-TCA-TAT-TC 3') and corresponding HPV probes [10] (the lowercase letters in the primer sequences are the Illumina adapter 
sequences added to the $5^{\prime}$ end of the original GP5+ and GP6+ primers [11] shown in uppercase letters). A $136 \mathrm{bp}$ fragment of human $\beta$-globin gene was coamplified as an internal control (Fig. 1).

In parallel, HPVs were also detected using an HTS approach based on the conventional HPV nested PCR. This PCR required both conventional MY09/11 primers (MY09, 5'-CGTCCMARRGGAWACTGATC-3', and MY11, 5'-GCMCAGGGWCATAAYAATGG-3', where $\mathrm{M}=\mathrm{A}$ or $\mathrm{C} ; \mathrm{R}=\mathrm{A}$ or $\mathrm{G}: \mathrm{W}=\mathrm{A}$ or $\mathrm{T} ; \mathrm{Y}=\mathrm{C}$ or $\mathrm{T}$ [12]) and the HTS-adapted GP5+/6+ primers. For HPV nested PCR, $5 \mu \mathrm{L}$ of each DNA sample was used for the first MY09/11 PCR and $2 \mu \mathrm{L}$ of the MY09/11 PCR products was used for the second GP5+/6+ PCR. The sequencing of amplicons and the analysis of generated data were carried out as described previously [10] (Fig. 1).

\section{Statistics}

Statistical analyses were performed using $\mathrm{R}$ software version 3.4.0. Cohen's Kappa value, a measure of agreement, was used to evaluate the concordance between the two HPV detection methods used here. The Kappa statistic varies from 0 to 1 , with unity indicating perfect agreement.

\section{Results}

HPV distribution among normal and dysplastic lesions with the AbRT assay and conventional nested PCR

The AbRT assay detected at least one HPV genotype in $44.57 \%$ of women $(37 / 83)$. The mean age of the women

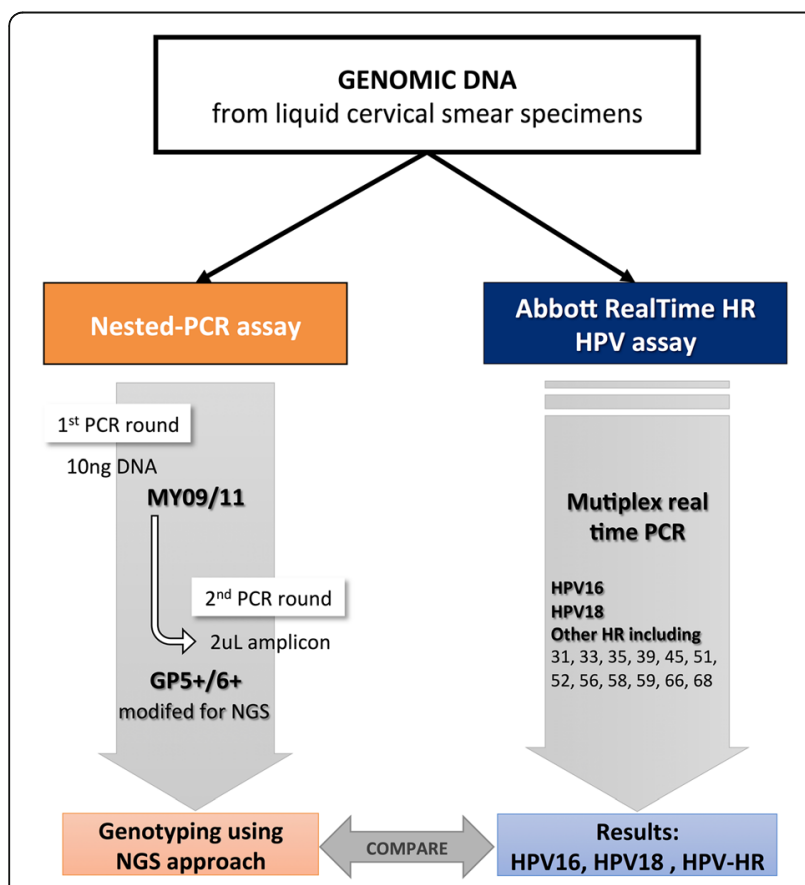

Fig. 1 Comparison of Nested-PCR and Abbott Realtime HR-HPV who were positive for HPV DNA was 50 years. HPVs (genotypes 16 and/or 18 and/or other targeted hrHPVs) were identified in $26 \%(13 / 50)$ and $72.72 \%(24 / 33)$ of cases among women presenting normal and abnormal cytology, respectively. Moreover, the association between abnormal cytology and HPV infection was significant ( $p$ value 0.001 ; odds ratio, $\mathrm{OR}=8.89)$ and increased with the severity of the cervical lesions and the age of the patient $(p<0.05)$. Although $10.81 \%(4 / 37)$ of the women were infected by at least two different categories of HPV (16 and/or 18 and/or other hrHPVs), HPV16 was the most frequently detected genotype, followed by other hrHPVs and HPV18 with detection rates of 52.63\%, $39.47 \%$ and $21.05 \%$, respectively.

The two methods used in this study demonstrated their ability to detect at least one hrHPV genotype (HPV16 or HPV18 or other hrHPV or a mix of several hrHPVs) among $100 \%(14 / 14)$ of the HSIL+ cases tested (Table 1). The nested PCR method detected more HPVs (56.5\% versus $33.3 \%$ ) among HSIL- samples than the AbRT assay (Table 1).

Among women presenting HSIL+ cervical abnormalities, HPV16 was detected by both methods in five cases of carcinoma and in five cases of HSIL (Table 2 and Table 3, cases no. 1 to 10). For two carcinoma cases (Table 3, cases no. 11 and 12), this genotype was only detected with the conventional nested PCR method. However, for these two cases, no discordant results for other detected genotypes (HPV18 and hrHPV for cases no. 11 and 12, respectively) were observed between the two methods. HPV18 was only detected with the AbRT assay in $50 \%(2 / 4)$ of cases in which it was identified with the nested PCR method (Table 2 and Table 3). For HSIL+ samples, the detection of genotypes HPV16 or HPV18 by both methods showed a moderate level of agreement of $85.71 \%$ with a Kappa value of 0.58 (Table 4).

Regarding women with ASCUS, LSIL and normal cytology, HPV16 was detected in 14.5\% (10/69) and 43.5\% (30/69) of cases by the AbRT assay and the nested PCR method, respectively (Table 2). HPV18 was found in $10.1 \%(7 / 69)$ and $15.9 \%(11 / 69)$ of cases by the AbRT assay and the nested PCR, respectively (Table 2 ). Among

Table 1 Comparison of HPV detection in high-grade lesions (HSIL+) between Abbott RealTime assay and conventional nested PCR

\begin{tabular}{llll}
\hline & & \multicolumn{2}{l}{ HSIL+ } \\
\cline { 3 - 4 } & & + & - \\
\hline Conventional nested PCR & + & 14 & 39 \\
Abbott RealTime & - & 0 & 30 \\
& + & 14 & 23 \\
& - & 0 & 46 \\
\hline
\end{tabular}


Table 2 Positive detection rate for each of the two tested assays according to cytological results: normal, atypical squamous cells of undetermined significance (ASCUS), low-grade lesions (LSIL) and high-grade lesions + (HSIL+)

\begin{tabular}{lllll}
\hline Assay & Normal $(n=50)$ & ASCUS $(n=12)$ & LSIL $(n=7)$ & HSIL+ $(n=14)$ \\
\hline Conventional nested PCR & $24(48 \%)$ & $6(50 \%)$ & $4(85.71 \%)$ & $14(100 \%)$ \\
HPV16 & $21(87.5 \%)$ & $4(66.67)$ & $4(66.67 \%)$ & $12(85.71 \%)$ \\
HPV18 & $5(20.8 \%)$ & $2(33.33)$ & $1(16.67 \%)$ & $3(21.43 \%)$ \\
Other high-risk genotypes & $15(62.5 \%)$ & $1(16.67)$ & $3(50 \%)$ & $4(28.57 \%)$ \\
Abbott RealTime & $13(26 \%)$ & $4(33.33 \%)$ & $6(85.71 \%)$ & $14(100 \%)$ \\
HPV16 & $7(53.85 \%)$ & $2(50 \%)$ & $2(33.33)$ & $1(16)$ \\
HPV18 & $1(7.69 \%)$ & $2(50 \%)$ & $4(71.43 \%)$ \\
Other high-risk genotypes & $7(53.85 \%)$ & - & $4(66.67 \%)$ & $3(14.29 \%)$ \\
\hline
\end{tabular}

all cases in which HPV16 and HPV18 were detected, only six and five cases were detected by both methods, respectively (Table 3 ). For LSIL, the two tested methods for detecting HPV16 and HPV18 showed moderate (78.95\%) and high agreement (94.74\%), with kappa values of 0.54 and 0.82 , respectively (Table 4 ).

\section{Identification of hrHPV (non-HPV16 and non-HPV18) genotypes detected with the AbRT assay}

Genotypes detected by the AbRT assay in the hrHPV category were compared with the results obtained from amplicons generated by the nested PCR method. The hrHPV category was detected in women presenting cytological abnormalities, with $14.28 \%(1 / 7)$, in $28.57 \%(2 / 7)$ and in $57.14 \%(4 / 7)$ of cases in carcinoma, HSIL and LSIL, respectively. Furthermore, the hrHPV category was also detected in $43.8 \%$ (7/10) of cases for women with normal cytology. Except for case no. 9, all HPV33 and HPV45 genotypes identified by PCR were also detected by the AbRT assay (Table 3, cases no. 10, 12 and 14) in HSIL+ samples. In case no. 9, HPV33 was only detected after sequencing the amplicon (Table 3).

Among all the LSIL samples tested, four samples tested positive with the AbRT assay, but only two (cases no. 17 and 26) were identified by both methods. Two cases (no. 21 and 22) were not identified by nested PCR, whereas for case no. 20, the AbRT assay failed to detect HPV33, which was identified by nested PCR. Among samples with normal cytology, at least one hrHPV genotype was detected in $94.7 \%(18 / 19)$ of cases by nested PCR (Table 3). However, in only $38.9 \%$ of cases $(7 / 18)$, the AbRT assay also indicated a positive signal for hrHPV. Unlike previous results for LSIL+ samples in which only one hrHPV genotype was detected each time, at least two hrHPV genotypes were detected in $22 \%$ of cases with normal cytology (Table 3 ). Finally, only the result for case no. 35 was discordant: the low-risk HPV72 genotype identified by nested PCR is not included in the hrHPV category detected with the AbRT assay.

\section{Discussion}

This study describes the first use of the Abbott RealTime High-Risk HPV assay for HPV detection in cervical cell samples of women with or without cervical abnormalities from a Gabonese female population. Moreover, this assay was compared with the use of conventional nested PCR coupled to HTS, which identifies the exact hrHPV genotypes revealed with the AbRT assay. The real-time PCR method (AbRT assay) can detect a total of 14 different high-risk HPV genotypes whereas the conventional nested PCR that uses the primers MY09/11 and GP5+/6 + can amplify around 30 different low- and high-risk HPV genotypes $[13,14]$. The genotypes are assayed from DNA extracted from cervical smears whose cervical anomalies have been revealed by a VIA/VILI test and confirmed by cytology. Although the manufacturer recommends using the Abbott automaton (m200sp, Abbott Molecular) with this assay for HPV detection, extractions were performed manually as described in literature as a practicable alternative. In a recent study, Kocjan et al. (2012) showed that similar results are obtained for HPV detection from biological tissues of head-neck squamous cell cancers regardless of the extraction method used with the AbRT assay [15, 16]. Moreover, we did not observe any differences in amplification intensity of the human $\beta$-globin (a housekeeping gene) between the AbRT kit and a classic qPCR protocol (data not shown).

In this study, the AbRT generally gave consistent genotyping results for the hrHPV screened in HSIL+ cases in comparison with the conventional nested PCR. These data are similar to other studies that compared the AbRT kit with this nested PCR method or with other molecular methods of HPV genotyping $[15,16]$. However, nested PCR appears to be more sensitive than the AbRT kit for the detection of hrHPV in HSIL- cases (i.e. LSIL, ASCUS and normal) even if in most cases, at least one hrHPV genotype was detected by both methods (Table 3). Given that the detection threshold of the AbRT assay is between 500 and 5000 genome copies, 
Table 3 Concordance between genotypes generated by conventional nested PCR (PCR GP) and the Abbott RealTime assay (AbRT) ( $P$, positive; N, negative; hrHPV, high-risk HPV, a category including 12 different hrHPV genotypes)

\begin{tabular}{|c|c|c|c|c|c|c|c|}
\hline Case number & PCR GP -HPV16 & AbRT - HPV16 & PCR GP -HPV18 & AbRT - HPV18 & PCR GP -hrHPV & AbRT - hrHPV & Cytology \\
\hline 1 & $P$ & $P$ & $\mathrm{~N}$ & $\mathrm{~N}$ & $\mathrm{~N}$ & $\mathrm{~N}$ & carcinoma \\
\hline 2 & $P$ & $P$ & $\mathrm{~N}$ & $\mathrm{~N}$ & $\mathrm{~N}$ & $\mathrm{~N}$ & carcinoma \\
\hline 3 & $P$ & $P$ & $\mathrm{~N}$ & $\mathrm{~N}$ & $N$ & $\mathrm{~N}$ & carcinoma \\
\hline 4 & $P$ & $P$ & $\mathrm{~N}$ & $\mathrm{~N}$ & $\mathrm{~N}$ & $\mathrm{~N}$ & carcinoma \\
\hline 5 & $P$ & $P$ & $\mathrm{~N}$ & $\mathrm{~N}$ & $\mathrm{~N}$ & $\mathrm{~N}$ & carcinoma \\
\hline 6 & $P$ & $P$ & $\mathrm{~N}$ & $\mathrm{~N}$ & $\mathrm{~N}$ & $\mathrm{~N}$ & HSIL \\
\hline 7 & $P$ & $P$ & $\mathrm{~N}$ & $\mathrm{~N}$ & $\mathrm{~N}$ & $\mathrm{~N}$ & HSIL \\
\hline 8 & $P$ & $P$ & $\mathrm{~N}$ & $\mathrm{~N}$ & $\mathrm{~N}$ & $\mathrm{~N}$ & HSIL \\
\hline 9 & $P$ & $P$ & $P$ & $\mathrm{~N}$ & 33 & $\mathrm{~N}$ & HSIL \\
\hline 10 & $P$ & P & $\mathrm{N}$ & $\mathrm{N}$ & 33 & P & HSIL \\
\hline 11 & $P$ & $\mathrm{~N}$ & $\mathrm{P}$ & $P$ & $\mathrm{~N}$ & $\mathrm{~N}$ & carcinoma \\
\hline 12 & $P$ & $\mathrm{~N}$ & $\mathrm{~N}$ & $\mathrm{~N}$ & 45 & $P$ & carcinoma \\
\hline 13 & $\mathrm{~N}$ & $\mathrm{~N}$ & $P$ & $P$ & $\mathrm{~N}$ & $\mathrm{~N}$ & HSIL \\
\hline 14 & $\mathrm{~N}$ & $\mathrm{~N}$ & $P$ & $\mathrm{~N}$ & 33 & $P$ & HSIL \\
\hline 15 & $P$ & $P$ & $N$ & $N$ & $N$ & $N$ & LSIL \\
\hline 16 & $P$ & $P$ & $\mathrm{~N}$ & $\mathrm{~N}$ & $N$ & $\mathrm{~N}$ & LSIL \\
\hline 17 & $P$ & P & $\mathrm{N}$ & $\mathrm{N}$ & 58 & P & LSIL \\
\hline 18 & $P$ & $P$ & $\mathrm{~N}$ & $\mathrm{~N}$ & $\mathrm{~N}$ & $\mathrm{~N}$ & LSIL \\
\hline 19 & $P$ & $N$ & $\mathrm{~N}$ & $\mathrm{~N}$ & $N$ & $N$ & LSIL \\
\hline 20 & $P$ & $\mathrm{~N}$ & $\mathrm{~N}$ & $\mathrm{~N}$ & $33 / 32$ & $\mathrm{~N}$ & LSIL \\
\hline 21 & $P$ & $N$ & $\mathrm{~N}$ & $\mathrm{~N}$ & $N$ & $P$ & LSIL \\
\hline 22 & $P$ & $\mathrm{~N}$ & $\mathrm{~N}$ & $N$ & $\mathrm{~N}$ & P & LSIL \\
\hline 23 & $\mathrm{~N}$ & $\mathrm{~N}$ & $P$ & $P$ & $\mathrm{~N}$ & $\mathrm{~N}$ & LSIL \\
\hline 24 & $\mathrm{~N}$ & $N$ & P & $P$ & $N$ & $\mathrm{~N}$ & LSIL \\
\hline 25 & $\mathrm{~N}$ & $\mathrm{~N}$ & $P$ & $P$ & $\mathrm{~N}$ & $\mathrm{~N}$ & LSIL \\
\hline 26 & $\mathrm{~N}$ & $\mathrm{~N}$ & $N$ & $\mathrm{~N}$ & 33 & $P$ & LSIL \\
\hline 27 & $\mathrm{~N}$ & $\mathrm{~N}$ & P & $N$ & $N$ & $\mathrm{~N}$ & LSIL \\
\hline 28 & P & $N$ & $\mathrm{~N}$ & $N$ & 31 & $\mathrm{~N}$ & normal \\
\hline 29 & P & $\mathrm{N}$ & $\mathrm{N}$ & $\mathrm{N}$ & 33 & $\mathrm{~N}$ & normal \\
\hline 30 & $\mathrm{~N}$ & $\mathrm{~N}$ & $\mathrm{~N}$ & $\mathrm{~N}$ & 33 & $P$ & normal \\
\hline 31 & $P$ & $N$ & $\mathrm{~N}$ & $N$ & 33 & P & normal \\
\hline 32 & $\mathrm{~N}$ & $\mathrm{~N}$ & $N$ & $N$ & 35 & P & normal \\
\hline 33 & $P$ & $\mathrm{~N}$ & $P$ & $P$ & 45 & $\mathrm{~N}$ & normal \\
\hline 34 & $\mathrm{~N}$ & $\mathrm{~N}$ & $\mathrm{~N}$ & $\mathrm{~N}$ & 58 & $\mathrm{~N}$ & normal \\
\hline 35 & $P$ & P & P & $\mathrm{N}$ & 72 & P & normal \\
\hline 36 & $P$ & $N$ & $P$ & $N$ & $33 / 35 / 45 / 58 / 72$ & $\mathrm{~N}$ & normal \\
\hline 37 & $P$ & $\mathrm{~N}$ & $P$ & $\mathrm{~N}$ & $33 / 45 / 58 / 72$ & $\mathrm{~N}$ & normal \\
\hline 38 & $\mathrm{P}$ & $\mathrm{N}$ & $\mathrm{N}$ & $\mathrm{N}$ & $33 / 45 / 72 / 81$ & $P$ & normal \\
\hline 39 & $P$ & $\mathrm{~N}$ & $\mathrm{~N}$ & $\mathrm{~N}$ & $33 / 58$ & $\mathrm{~N}$ & normal \\
\hline 40 & $\mathrm{P}$ & $P$ & $P$ & $P$ & $33 / 72$ & $P$ & normal \\
\hline 41 & $\mathrm{~N}$ & $\mathrm{~N}$ & $\mathrm{~N}$ & $\mathrm{~N}$ & $35 / 72$ & $\mathrm{~N}$ & normal \\
\hline 42 & $P$ & $N$ & $\mathrm{~N}$ & $\mathrm{~N}$ & $45 / 72$ & $P$ & normal \\
\hline 43 & $P$ & $\mathrm{~N}$ & $\mathrm{~N}$ & $\mathrm{~N}$ & $\mathrm{~N}$ & $\mathrm{~N}$ & normal \\
\hline
\end{tabular}


Table 4 Agreement (\%) between the Abbott RealTime and conventional nested PCR assays for the detection of the HPV16 and HPV18 genotypes among high-grade lesions (HSIL+) and low-grade lesions (LSIL)

\begin{tabular}{llll}
\hline & & HSIL+ & HSIL- \\
\hline HPV16 & Agreement & 85.71 & 78.95 \\
& Kappa coefficient & 0.58 & 0.54 \\
HPV18 & Agreement & 85.71 & 94.74 \\
& Kappa coefficient & 0.58 & 0.82 \\
\hline
\end{tabular}

genotypes detected using both methods in this study may have a higher number of copies than this threshold [17], suggesting that cases for which only one genotype was detected by the nested PCR method contain fewer than 500 copies. However, this hypothesis remains to be tested because we have no data on the actual viral loads of our samples. Furthermore, although the correlation between the number of reads and viral load is not perfect, cases with genotypes detected by both methods were generally those with highest numbers of sequenced reads [10]. Owing to the depth of sequencing with a minimum of several hundred thousand reads per sample, a minor HPV genotype can be detected if it is represented in at least $2 \%$ of the total reads [10]. Therefore, in a given sample, HTS can unambiguously detect several genotypes whose relative proportions potentially vary $[18,19]$. Moreover, although the sequenced amplicon size was only $150 \mathrm{bp}$, this region of the $\mathrm{L} 1$ gene is highly amenable to molecular analysis, which can discriminate between the different HPV genotypes. Finally, the HTS approach for sequencing HPV amplicons may overcome the limit of direct amplicon sequencing using the Sanger method, which is simple to implement from a biopsy, but cannot be performed on DNA extracted from a (LBC) cervical smear, especially when the cytological grade is low or normal, due to the potential simultaneous presence of several HPV genotypes [20]. Although HPV genotyping assays using consensus or broad-spectrum primers are less sensitive than typespecific or targeted primers [21], consensus PCR is less affected by competitive primer binding in mixed HPV infections. For instance, the presence of high viral loads of HPV16 or, in some cases, the presence of some hrHPVs can mask the HPV52 genotype in anogenital samples [22] or inhibit the amplification and detection of HPV31 and 33 [23]. Moreover, unfavorable amplification kinetics may occur when an HPV genotype belonging to the alpha- 9 subgenus is in the presence of other genotypes (Iftner et al. (2016).

Several studies have shown that the sensitivity of the AbRT assay is similar to that of the hc2 test and that the specificity of detection of HPVs associated with the development and/or spread of $\mathrm{CIN} 2+$ can reach
$92 \%[16,24,25] . \mathrm{GP} 5+/ 6+$ PCR has the same clinical performance as the hc2 test [8]. However, the addition of the first nested PCR step with MY09/11 primers improves the sensitivity of the conventional PCR test, but leads to a decrease in its specificity for the detection of HPV genotypes shown to be associated with the development of HSIL+ into cancer [26]. Furthermore, the nature of the samples used in this study clearly influences the differences observed between the two methods. In contrast to samples from biopsies, LBC samples recover numerous superficial cells in addition to the cells located in a putative precancerous lesion. However, these superficial cells may be infected by the same hrHPV genotype or other hrHPV genotypes. The use of a sensitive HPV detection method may reveal these supplementary infections and not just the HPV implicated in the (pre)cancerous lesion. In effect, due to this high sensitivity, most studies on the clinical validation of HPV detection tests are carried out on FFPE tissue blocks, not LBC samples, and cytological results are generally confirmed by a histological analysis to confirm the grade of the observed lesion. Therefore, the differences between the two molecular methods for HPV detection are most likely due to the nature of the samples used in this study and may have led to variation in the performance of the test and the specificity of the AbRT compared with the data found in literature [15, 24, 27-29]. However, the use of LBC led to a better preparation of the sample associated with an enhanced quality of the cytological results. Recent studies have shown improved slide reading when LBC systems are used instead of conventional Pap smears in a routine clinical setting. Moreover, LBC using PreservCyt (Thinprep) has been approved by the FDA for molecular HPV tests [30]. This FDA approval provides the opportunity to carry out two biological analyses from a single sample, a certain advantage in low-income countries or when the population has limited access to healthcare.

\section{Conclusions}

This study on the performance of the AbRT assay shows that it is an easy and reliable molecular tool for HPV detection in HSIL+ LBC samples. However, as expected, the AbRT assay is less sensitive than conventional nested PCR for the detection of HPV in HSIL-. Moreover, the sequencing of amplicons using a HTS approach effectively identified the genotype of hrHPV detected with the AbRT assay. Finally, our data showed that the use of AbRT in co-testing with VIA/VILI in low-income countries holds promise as an interesting alternative to other combinations, such as VIA and cytology. 


\section{Abbreviations}

AbRT: Abbott RealTime; ASCUS: Atypical squamous cells of undetermined significance; CIN: Cervical intra-epithelial neoplasia; FDA: Food and Drug Administration; FFPE: Formalin-fixed paraffin-embedded; HPV: Human papillomavirus; hrHPV: high-risk human papillomavirus; HSIL: High-grade squamous intraepithelial lesion; HTS: High-throughput sequencing; LBC: Liquidbased cytology; LSIL: Low-grade squamous intraepithelial lesion; VIA: Visual inspection with acetic acid; VILI: Visual inspection with Lugol's iodine

\section{Acknowledgements}

We would like to acknowledge Heïdi Lançon and Dr. Carolyn Engel-Gautier for her revision of English usage and grammar throughout the manuscript. The authors wish to thank all the Gabonese women who participated in this study and Nyangui Pongui Marcelle Flore for management of the patients included in this study.

\section{Funding}

This study was supported by the CIRMF. The CIRMF is supported by the Government of Gabon, Total-Fina-Elf Gabon, and the Ministère de la Coopération Française. The funders had no role in study design, data analysis or preparation of the manuscript.

\section{Availability of data and materials}

The datasets analyzed during the current study are available from the corresponding author on reasonable request.

\section{Authors' contributions}

NB conceived and designed the study. PBM performed all the molecular biology assays for HPV genotyping and performed the statistical analysis. All authors analyzed the data. PBM, IL and NB wrote the manuscript. NB, EL and IHK, EB were involved in the project implementation at the CIRMF and at $I C L$, respectively. $I L$ and $I H K$ critically read the manuscript. All authors read and approved the final manuscript.

\section{Ethics approval and consent to participate}

This study was approved by the Medical Ethics Committee of Gabon (consent number PROT no. 0010/2013/SG/CNE), and was authorized by the Gabonese Ministry of Health (no. 00775/MS/CAB.M/SG/DGS) and the Scientific Committee of the Centre International de Recherches Médicales de Franceville (CIRMF). All women included in this study signed a specific consent forms that authorized the use of their cervical samples.

\section{Consent for publication}

All authors approved the final manuscript.

\section{Competing interests}

The authors have no competing interests to report.

\section{Publisher's Note}

Springer Nature remains neutral with regard to jurisdictional claims in published maps and institutional affiliations.

\section{Author details \\ ${ }^{1}$ Centre International de Recherches Médicales de Franceville (CIRMF), Department of Zoonosis and Emerging Diseases, 769 Franceville, BP, Gabon. ${ }^{2}$ Institut de Cancérologie de Libreville (ICL), Libreville, Gabon. ${ }^{3}$ Institut de Recherches et de Développement (IRD), Maladies Infectieuses et vecteurs : Ecologie, Génétique, Evolution et Contrôle (IRD 224 - CNRS 52906 UM1- UM2), Montpellier, France. ${ }^{4}$ Centre National de Recherche Scientifique (CNRS), UMR3569, 25 rue du docteur Roux, 75724 Paris, France. ${ }^{5}$ Institut Pasteur, Unité Environnement et risques infectieux, Cellule d'Intervention Biologique d'Urgence, 25 rue du Docteur Roux, 75724 Paris, France.}

Received: 30 June 2017 Accepted: 4 December 2017

Published online: 21 December 2017

\section{References}

1. Bruni L. B-RL, Albero G., Aldea M., Serrano B., Valencia S., Brotons M., Mena M. Cosano R., Munoz J., Bosch FX., de Sanjosé S., Castellsagué X., ICO Information Centre on HPV and Cancer (HPV Information Centre): Human Papillomavirus and Related Diseases in the World. Summary Report 2014:12-18.
2. Bosch FX, Lorincz A, Munoz N, Meijer CJ, Shah KV. The causal relation between human papillomavirus and cervical cancer. J Clin Pathol. 2002; 55(4):244-65.

3. Burd EM. Human papillomavirus and cervical cancer. Clin Microbiol Rev. 2003;16(1):1-17.

4. Katki HA, Kinney WK, Fetterman B, Lorey $T$, Poitras NE, Cheung L, Demuth F, Schiffman M, Wacholder S, Castle PE. Cervical cancer risk for women undergoing concurrent testing for human papillomavirus and cervical cytology: a population-based study in routine clinical practice. Lancet Oncol. 2011;12(7):663-72.

5. Cuzick J, Clavel C, Petry KU, Meijer CJ, Hoyer H, Ratnam S, Szarewski A, Birembaut $P$, Kulasingam $S$, Sasieni $P$, et al. Overview of the European and north American studies on HPV testing in primary cervical cancer screening. Int J Cancer. 2006;119(5):1095-101.

6. Bulkmans NW, Berkhof J, Rozendaal L, van Kemenade FJ, Boeke AJ, Bulk S, Voorhorst FJ, Verheijen RH, van Groningen K, Boon ME, et al. Human papillomavirus DNA testing for the detection of cervical intraepithelial neoplasia grade 3 and cancer: 5-year follow-up of a randomised controlled implementation trial. Lancet. 2007;370(9601):1764-72.

7. Cubie HA, Cuschieri K. Understanding HPV tests and their appropriate applications. Cytopathology. 2013:24(5):289-308.

8. Meijer CJ, Berkhof J, Castle PE, Hesselink AT, Franco EL, Ronco G, Arbyn M, Bosch FX, Cuzick J, Dillner J, et al. Guidelines for human papillomavirus DNA test requirements for primary cervical cancer screening in women 30 years and older. Int J Cancer. 2009;124(3):516-20.

9. Santesso N, Mustafa RA, Schunemann HJ, Arbyn M, Blumenthal PD, Cain J, Chirenje M, Denny L, De Vuyst H, Eckert LO, et al. World Health Organization guidelines for treatment of cervical intraepithelial neoplasia 23 and screen-and-treat strategies to prevent cervical cancer. Int J Gynaecol Obstet. 2016:132(3):252-8.

10. Moussavou PB, Koumakpayi IH, Nkili-Meyong AA, Labouba I, Bisvigou U, Chansi JK, Engohan-Aloghe C, Dissanami F, Ambounda N, Delannoy-Vieillard AS, et al. Molecular analysis of human Papillomavirus detected among women positive for cervical lesions by visual inspection with acetic acid/Lugol's iodine (VIAVILI) in Libreville, Gabon. Infect Agent Cancer. 2016;11(1):50.

11. de Roda Husman AM, Walboomers JM, van den Brule AJ, Meijer CJ, Snijders PJ. The use of general primers GP5 and GP6 elongated at their 3' ends with adjacent highly conserved sequences improves human papillomavirus detection by PCR. J Gen virology. 1995;76(Pt 4):1057-62.

12. Schiffman MH, Bauer HM, Hoover RN, Glass AG, Cadell DM, Rush BB, Scott DR, Sherman ME, Kurman RJ, Wacholder S, et al. Epidemiologic evidence showing that human papillomavirus infection causes most cervical intraepithelial neoplasia. J Natl Cancer Inst. 1993;85(12):958-64.

13. Harwood CA, Spink PJ, Surentheran T, Leigh IM, de Villiers EM, McGregor JM, Proby CM, Breuer J. Degenerate and nested PCR: a highly sensitive and specific method for detection of human papillomavirus infection in cutaneous warts. J Clin Microbiol. 1999;37(11):3545-55.

14. Remmerbach TW, Brinckmann UG, Hemprich A, Chekol M, Kuhndel K, Liebert UG. PCR detection of human papillomavirus of the mucosa: comparison between MY09/11 and GP5+/6+ primer sets. J Clinical Virol. 2004;30(4):302-8.

15. Kocjan BJ, Maver PJ, Hosnjak L, Zidar N, Odar K, Gale N, Poljak M. Comparative evaluation of the Abbott RealTime high risk HPV test and INNO-LiPA HPV genotyping extra test for detecting and identifying human papillomaviruses in archival tissue specimens of head and neck cancers. Acta Dermatovenerol Alp Pannonica Adriat. 2012;21(4):73-5.

16. Poljak M, Ostrbenk A, Seme K, Sterbenc A, Jancar N, Vrtacnik Bokal E. Threeyear longitudinal data on the clinical performance of the Abbott RealTime high risk HPV test in a cervical cancer screening setting. J Clin Virol. 2015;

17. Huang S, Tang N, Mak WB, Erickson B, Salituro J, Li Y, Krumpe E, Schneider G, Yu H, Robinson J, et al. Principles and analytical performance of Abbott RealTime high risk HPV test. J Clin Virol. 2009:45(Suppl 1):S13-7.

18. Salipante SJ, Sengupta DJ, Rosenthal C, Costa G, Spangler J, Sims EH, Jacobs MA, Miller SI, Hoogestraat DR, Cookson BT, et al. Rapid 16S rRNA nextgeneration sequencing of polymicrobial clinical samples for diagnosis of complex bacterial infections. PLoS One. 2013:8(5):e65226.

19. Shendure J, Ji H. Next-generation DNA sequencing. Nat Biotechnol. 2008; 26(10):1135-45.

20. Gailey MP, Stence AA, Jensen CS, Ma D. Multiplatform comparison of molecular oncology tests performed on cytology specimens and formalinfixed, paraffin-embedded tissue. Cancer Cytopathol. 2015;123(1):30-9. 
21. Tota JE, Ramanakumar AV, Jiang M, Dillner J, Walter SD, Kaufman JS, Coutlee F, Villa LL, Franco EL. Epidemiologic approaches to evaluating the potential for human papillomavirus type replacement postvaccination. Am J Epidemiol. 2013;178(4):625-34.

22. Tota JE, Ramanakumar AV, Villa LL, Richardson H, Burchell AN, Koushik A, Mayrand MH, Coutlee F, Franco EL. Evaluation of human papillomavirus type replacement postvaccination must account for diagnostic artifacts: masking of HPV52 by HPV16 in anogenital specimens. Cancer Epidemiol Biomark Prev. 2015;24(1):286-90.

23. Cornall AM, Phillips S, Cummins E, Garland SM, Tabrizi SN. In vitro assessment of the effect of vaccine-targeted human papillomavirus (HPV) depletion on detection of non-vaccine HPV types: implications for postvaccine surveillance studies. J Virol Methods. 2015;214:10-4.

24. Cid Arregui A, Gariglio P, Kanda T, Doorbar J. ONCOGENIC HUMAN PAPILLOMAVIRUSES: high-risk human Papillomaviruses: towards a better understanding of the mechanisms of viral transformation, latency and immune-escape. Open Virol J. 2012;6:160-2.

25. Cuzick J, Ambroisine L, Cadman L, Austin J, Ho L, Terry G, Liddle S, Dina R, McCarthy J, Buckley H, et al. Performance of the Abbott RealTime high-risk HPV test in women with abnormal cervical cytology smears. J Med Virol. 2010;82(7):1186-91.

26. Cuzick J, Mayrand MH, Ronco G, Snijders P, Wardle J. Chapter 10: new dimensions in cervical cancer screening. Vaccine. 2006;24(Suppl 3):S3/90-7.

27. Choi J, Park Y, Lee EH, Kim S, Kim JH, Kim HS. Detection and genotyping of human papillomavirus by five assays according to cytologic results. J Virol Methods. 2013:187(1):79-84.

28. Chung HS, Hahm C, Lee M. Comparison of the clinical performances of the AdvanSure HPV screening real-time PCR, the Abbott real-time high-risk HPV test, and the hybrid capture high-risk HPV DNA test for cervical cancer screening. J Virol Methods. 2014;205C:57-60.

29. Hesselink AT, Meijer CJ, Poljak M, Berkhof J, van Kemenade FJ, van der Salm ML, Bogaarts M, Snijders PJ, Heideman DA. Clinical validation of the Abbott RealTime high risk HPV assay according to the guidelines for human papillomavirus DNA test requirements for cervical screening. J Clin Microbiol. 2013:51(7):2409-10.

30. Gibb RK, Martens MG. The impact of liquid-based cytology in decreasing the incidence of cervical cancer. Rev Obstet Gynecol. 2011;4(Suppl 1):S2-S11.

\section{Submit your next manuscript to BioMed Central and we will help you at every step:}

- We accept pre-submission inquiries

- Our selector tool helps you to find the most relevant journal

- We provide round the clock customer support

- Convenient online submission

- Thorough peer review

- Inclusion in PubMed and all major indexing services

- Maximum visibility for your research

Submit your manuscript at wuw biomedcentral.com/submit

) Biomed Central 